\title{
Leadership Styles and Organizational Performance of Employees: The Case of Some Primary and Secondary Schools in Cameroon
}

\author{
Matiedem Tiefang Huguette Silamine ${ }^{1}$, Njengoué Ngamaleu Henri Rodrigue ${ }^{2}$
}

\begin{tabular}{l} 
ARTIC LE INFO \\
\hline Article History: \\
Received 11.11 .2019 \\
Received in revised form \\
30.09 .2020 \\
Accepted \\
Available online 01.01 .2021
\end{tabular}

\section{INTRODUCTION}

Today, the competitive environment in which organizations operate is expanding globally and bringing them too many challenges. Thus, in order to achieve their objectives, organizations must have leaders who can stimulate employees to achieve said objectives. And to do this, organizational managers must seek the appropriate leadership style to better manage their organizations. As a school is an organization, we believe that it is good for the leading school head to rely on a leadership style that must lead his or her employees to achieve the expected results through good organizational performance. There are several types of leadership that can help the school leader to encourage his collaborators to work very well and deliver results beyond their own expectations. In the case of this study, we will refer to transformational and transactional leadership.

\section{Transformational Leadership}

Bass and Riggio, (2006) worked on the two leadership styles that we will elucidate in the following lines. For these authors, transformational leadership is about inspiring followers to engage, share a vision and goals for an organization or unit, challenge them to solve problems in innovative ways and develop the leadership capacity of practitioners through coaching, mentoring, challenge and support delivery. The transformational leader gives vision and sense of mission, instilling pride, gain, respect and trust (Bass, 1990

\footnotetext{
${ }^{1}$ hugetteslamin@gmail.com, University of Yaoundé , orcid.org/0000-0002-4901-8725

2ngamaleurodrigue@gmail.com, University of Yaoundé ,orcid.org/0000-0002-3742-0821
} 
Silamine,M.T.H. \& Rodrigue,N.N.H.(2021).Leadership styles and organizational performance of employees: The case of some primary and secondary schools in Cameroon. International Journal of Educational Research Review,6(1),30-45.

cited by Paracha and al, 2012). Thus, transformational leadership allows the leader to adapt strategies to stimulate employees to get more involved in the workplace in order to perform well and face global competition. This is probably why Doody and Doody (2011) believe that one of the key success factors in today's businesses is its ability to survive in a constantly changing market environment that requires greater flexibility, innovative and transformational leadership. Transformational leadership has four dimensions that were conceptualized by Bass (1985) and developed by Bass and Riggio (2006). With regard to Idealized Influence, leaders behave in a way that serves as a model for their followers and they are admired, respected and trusted. Followers identify with leaders and seek to imitate them and the leaders are endowed by subordinates with extraordinary abilities, perseverance and determination. With regard the Inspiring Motivation, transformational leaders behave in ways that motivate and inspire those around them by giving meaning and challenging the work of their followers. Team spirit is alive, enthusiasm and optimism are displayed. As for the Intellectual Stimulation, it manifests by the leader's ability to induce new ways of thinking in subordinates (Silins, 1992 cited by Morin \& Dussault 1999), and to induce subordinates to become aware of problems and to reflect on possible solutions (Morin \& Dussault, 1999). The Individualized Consideration it manifests by transformational leaders who pay particular attention to each participant's needs for success and growth by acting as a coach or mentor. Thus, followers and colleagues are developed at higher levels of potential (Bass \& Riggio, 2006).

The second dimension of the Bass (1985) model is transactional leadership.

For Sillins (1992 cited by Morin \& Dussaut 1999), the transactional leader is the one who knows how to motivate his subordinates to act in accordance with the expectations of the organization through an exchange aimed at satisfying basic needs. As a result, transactional leadership can be seen as a contract that binds employees to the leader and allows them to get more involved in the work for fear of being punished. It is in this momentum that Bradley and Charbonneau (2004) believe that transactional leadership is characterized by exchanges in which leaders motivate subordinates by rewarding them for their efforts or punishing them for their lack of effort. Transactional leadership includes two types of behaviour: taskrelated reward and leadership by exception. The reward linked to the task called the Contingent Reward of the Transactional Leader (RCLT): this concept refers to the set of behaviours which consists in encouraging subordinates in the practice of their functions. According to Bass and Riggio (2006), the direction of conditional rewards involves awarding or obtaining a follow-up agreement on what must be done with promised or actual rewards offered in exchange for satisfactory performance of the mission. The Bass model includes two types of steering: active and passive. The first one called Active Exception Management refers to a careful leader. Here, the leader is responsible for actively monitoring deviations from standards, errors and errors in the follower's tasks and taking corrective action (Bass \& Riggio, 2006). The second called Passive Exception Management refers to a passive leader who only intervenes when problems are serious.

The organizational performance of work 
Silamine,M.T.H. \& Rodrigue,N.N.H.(2021).Leadership styles and organizational performance of employees: The case of some primary and secondary schools in Cameroon. International Journal of Educational Research Review,6(1),30-45.

Goodman and al cited by Morin and al (1999) then by Boujlida (2002) underline that the answer to the question "what is organizational performance" is far from being as simple as one might think because even if the literature abounds on this subject there is no consensus on the definition of the subject or on how to measure it. This means that the performance is not objective and each author defines it according to his angle of approach. As a result, organizational performance is related to the effectiveness of the organizational structure (Kalika, 1988; Kaplan \& Norton, 1992; Morin \& al, 1994 cited by Zineb, 2017). Organizational performance refers to an organization's ability to achieve its objectives by using its resources effectively and efficiently (Daft, 2000 cited by Abasilim, 2014). According to this definition, a person is effective if he or she meets the formal requirements of the definition of his or her tasks. It is in this sense that some authors such as Ged (1983 cited by Boujlida, 2002) believe that performance is a one-dimensional concept and is measured by a single indicator such as profitability, productivity or stability. However, it should be noted that Economic growth has broadened this concept, which initially focused solely on the task, that is to say on productivity, because in reality there are other factors that can influence performance. Hence its multidimensional aspect. From a multidimensional point of view, the definition of performance incorporates several indicators that are listed by Zined (2017) in the definition he proposes to the notion of performance. Thus, for him, performance is how the company is organized to achieve its objectives and how it manages to achieve them. It incorporates various indicators such as product and service quality, employee engagement, work climate, productivity, customer satisfaction, etc. In the same vein, Cotonnec and Gallois, 2001 cited by Benlalam, 2015) identified four performance indicators: satisfaction, level of learning, corporate culture and employee and company productivity. Thus, to better understand organizational performance, it is necessary to define or explain each performance indicator mentioned above by Cotonnec and Dallois (2001).

\section{The different performance indicators}

According to Lorino (2001 cited by Benlalam 2015), we are talking about process indicators or steering when it comes to conducting an action in progress and we are talking about outcome indicators when it comes to evaluating the outcome of a completed action. In this study, we grouped our indicators in terms of process and results. The first process indicator we have identified is satisfaction: Satisfaction and of course employee satisfaction at work is a general expression of workers' positive attitudes towards their jobs (Man and al, 2011 cited by Khoza, 2015). This is generally the employee's job satisfaction (Danish et al, 2015) cited by the same author. The second process indicator is corporate culture. According to Akanni (1997), corporate culture is a priori a set of beliefs, representations about the organization, how to act and behave there. The culture applied in a company thus allows the characteristic and distinguished of others thanks to its principles, values, mission and commitment to work. In relation to the study, the representation of staff of their school head is a factor that influences school performance. As a result, the school head must be the one who creates a school climate conducive to change, who knows how to listen to his employees and who gives each employee the opportunity to express themselves and to have a participatory right in the organization of 
Silamine,M.T.H. \& Rodrigue,N.N.H.(2021).Leadership styles and organizational performance of employees: The case of some primary and secondary schools in Cameroon. International Journal of Educational Research Review,6(1),30-45.

work within the school. Thus, school leadership influences the school culture and the work of teachers who in turn have an impact on school performance (Marzano and al, 2016 cited by Lamothe, 2017). The third process indicator cited by Lorino is learning.

When we talk about learning within the organisation, we are talking about continuing vocational training within the organisation or seminars which aim to improve the performance of employees in order to make them more competent. Continuing vocational training is part of the continuing education of employees within the company. It is therefore intended to enable workers to adapt to changes in techniques and working conditions and to promote their social advancement through access at different levels of culture and professional qualification and their contribution to cultural, economic and social development (Francis, 2003).

As an outcome indicator, we have productivity. In general, productivity refers to the production capacity of an input or group of inputs within a given time period (Da Silva and Santugini, 2009). Productivity measurement provides information on the efficiency with which resources are transformed into production. This is how we talk about labour productivity, which is a measure that informs on the efficiency with which workers transform their efforts into production. This is calculated from the ratio of total production to the amount of labour required to produce it (Da Silva \& Santugini, 2009).

\section{Situation of the problem}

Leadership and especially leadership styles have attracted the attention of researchers for several years. In this momentum, Jamaludin (2011 cited by Paracha, Qamar, Mirza, Hassan \& Waqas (2012) Conducted research on leadership and their styles and suggested that effective leaders are those who use their powers to improve followers and organization. in this vein, Lievens and al, (1997), say leaders are one of the key drivers of improved production and innovation. Most researchers emphasized transformational leadership (Rejas, Ponce, \& Almonte, 2006; Muterera, 2012) but some also placed importance on transactional leadership (Obiwuru, Okwu,Akpa \& Nwankere ,2011; Paracha and al, 2012). Pradeep and Prabhu (2011) found in their studies that leadership is positively related to employee performance in both transformational and transactional behaviour. Given that, in the Cameroonian context little research has been done on leadership style in the education sector. For that reason, we want to focus our research on these two leadership styles (transactional and transformational) developed by Bass in 1985 to see if these two leadership styles better predict the organizational performance of employees' work in the schools of the city of Yaoundé.

\section{Aim of the study}

The aim of the present study is to predict the organizational performance of employees' work according to the leadership style of both primary and secondary school heads of the city of Yaoundé. Indeed, we want to draw the attention of school leaders to the possibility they have of influencing the organizational 
Silamine,M.T.H. \& Rodrigue,N.N.H.(2021).Leadership styles and organizational performance of employees: The case of some primary and secondary schools in Cameroon. International Journal of Educational Research Review,6(1),30-45.

performance of their collaborators through their leadership styles in such a way that they are more involved in school work to deliver results beyond their own expectations. Specifically:1) describe the relationship between the modalities of transformational and transactional leadership, between them, on the one hand, and with those of organizational performance, on the other hand; 2) test the influence of different sociodemographic variables likely to be related to the said performance; and 3) develop a hierarchical regression equation predicting organizational performance using significant independent variables.

\section{METHOD}

\section{Participants}

We compiled a sample of 345 employees in primary, general secondary and technical schools in the city of Yaoundé. As far as the categories of schools are concerned, $49.9 \%$ of the staff are from the public sector, $31 \%$ from the secular private sector and $10.7 \%$ from the Catholic denominational private sector. As far as the level of intervention is concerned, $50.4 \%$ of the school head's employees work in primary education, $24.9 \%$ in general secondary education and $16.2 \%$ in technical secondary education. As regards the education sub-system, 54.5\% of the school head's staff are Francophone, 7.2\% are Anglophone and 29.9\% are bilingual. Apart from 29 persons who did not provide information on their level of education, religious commitments, number of teaching hours per week and sex of their head of school, 131 others, or $38 \%$ of valid pupils, 214 or $62 \%$ of the workforce are women. Married persons are the most represented in the sample (49\%) compared to $21.5 \%$ of the total, $25 \%$ of single persons and $4.5 \%$ of divorced persons. As far as the position of responsibility is concerned, $84.3 \%$ of the school head's employees claim to be teachers, $4.3 \%$ are general supervisors, $2.3 \%$ are office managers, $1.4 \%$ are vice principals, $1.2 \%$ are bursars, $2.6 \%$ are deputy directors and $3.8 \%$ hold other positions. The ten regions of Cameroon are variously represented in the sample and nationals of the western region are more numerous (25.5\%) followed by those of the Centre $(24.3 \%)$, the North-West $(9.9 \%)$ and the South $(7.8 \%)$. With regard to the level of study, graduates and masters are the most represented. Teachers holding the Master's Degree as well as those holding the Bachelor's Degree have a staff of 88 each, meaning 25.5\% for the Bachelor's Degree and 25.5\% for the Master Degree. In terms of seniority, the average age is 8.58 ; the oldest are 32 years old and the youngest have one year of service. On the level of religious commitment, it is clear that the sample is mostly Christian because $36.8 \%$ of the staff of the head of the school say they are engaged in religious life, 13\% say they are very engaged, $25.8 \%$ say they are moderately engaged. With regard to the number of years of service under the current head teacher, the average age is $3.23 \%$ because the majority say they have completed at most 3 years with their heads of school. As regards the number of teaching hours per week, the average number of hours is $21.37 \%$ because the majority of teachers, especially those in primary education, make on average 25 hours of lessons per week. As regards the sex of the head teacher, $54.5 \%$ are female $45.5 \%$ are male. So the principals are mostly women.

\section{Material and Procedure}


Silamine,M.T.H. \& Rodrigue,N.N.H.(2021).Leadership styles and organizational performance of employees: The case of some primary and secondary schools in Cameroon. International Journal of Educational Research Review,6(1),30-45.

Since the independent variable consists of two factors, namely transformational leadership and transactional leadership. Each factor has been operationalized empirically in four modalities for the first and three modalities for the second respectively. The modalities of transformational leadership are: idealized influence (example of item: I see my school head as a role model); inspiring motivation (example of item: my school head encourages team spirit); intellectual stimulation (example of item: my school head encourages me to be creative and innovative) and individual consideration (example of item; my school head is worried about my personal development). In terms of transactional leadership, our terms and conditions are: the head of the institution's dependence on unconditional rewards (example of item: my head of the institution encourages me to achieve the agreed objectives); management by active exception (example of item; my superintendent sets performance standards); passive exception management (ex-item: my superintendent only deals with serious issues). The dependent variable (organisational performance) has also been operationalized empirically in four ways: satisfaction (example of item: head of establishment encourages personal initiative); learning (example of item: the head teacher is actively concerned with the intellectual capital of his pupils); the culture of the school (example of item: you find that the school climate is positive) and productivity (example of item: how do you estimate the satisfaction rate of the parents of students?). Apart from the productivity items from 1 (very low) to 4 (very high) all the other items correspond to ordinal measurement scales. These are precisely the 4-level Likert scales for independent variables (not at all agree -1-2-3-4- totally agree) and the 4-level Likert inverted scale for the dependent variable (totally agree-12-3-4 totally disagree).

Table 1 provides information on Crombach alpha values based on normalized elements for all measured dimensions. They were calculated during the data collection of 345 employees of heads of primary and secondary schools in the city of Yaoundé. Note that internal consistency is satisfied for all dimensions.

Table 1: Summary of the various Crombach $(\alpha)$ alphas of the measuring instruments

\begin{tabular}{|c|c|c|c|}
\hline Variable & Dimension & $\begin{array}{r}\text { Alpha by } \\
\text { Crombach }(\alpha) \\
\end{array}$ & $\begin{array}{l}\text { Items } \\
\text { number }\end{array}$ \\
\hline \multirow[t]{5}{*}{ Transformational leadership } & & .933 & 22 \\
\hline & idealized Influence & .807 & 7 \\
\hline & inspiring motivation & .819 & 4 \\
\hline & intellectual stimulation & .863 & 5 \\
\hline & individual consideration & .825 & 6 \\
\hline \multirow[t]{5}{*}{ Transactional leadership } & & .735 & 14 \\
\hline & dependence of head of establishment & .686 & \\
\hline & on unconditional rewards & & 5 \\
\hline & management per active exception & .802 & 5 \\
\hline & management per passive exception & .538 & 4 \\
\hline \multirow[t]{5}{*}{ Organizational performance } & & .819 & 26 \\
\hline & Satisfaction & .704 & 4 \\
\hline & Learning & .814 & 7 \\
\hline & school culture & .854 & 7 \\
\hline & school productivity & .850 & 8 \\
\hline
\end{tabular}

\section{Data Analyses}


Silamine,M.T.H. \& Rodrigue,N.N.H.(2021).Leadership styles and organizational performance of employees: The case of some primary and secondary schools in Cameroon. International Journal of Educational Research Review,6(1),30-45.

Once the data is entered into the IBM SPSS-Amos 22, the average scores of the different modalities of transformational and transactional leadership and organizational performance at work were calculated by summing the responses to the items measuring them, then dividing this score by the number of items. Concerning these three dimensions themselves, the scores by their modalities are also summed and divided by the number of modalities. This operation produces averages that relate to the levels of the scale used. Subsequently, the Test of Student is applied to compare the average scores with the median of the scale (2.5 for leadership and 3 for organizational performance at work), which makes it possible to determine the significance of the difference. The relationships between the different leadership modalities are examined using bivariate correlations. The rest of the analysis focuses on each of the socio-demographic variables measured by studying the link with the two leaderships and organizational performance at work, all quantitative variables. Therefore, when the demographic variable is qualitative and dichotomous, the Test of Student is used this time to compare two independent sample averages. When qualitative demographic variables have more than two modalities, as is the case for most, the variance analysis test (ANOVA) is used to compare Means. For quantitative variables, the Pearson correlation test is again used. With a review of the influence of demographic variables, those that prove to be related to organizational performance at work are retained for the continuation of the analysis which consists of a hierarchical regression aiming at the prediction of said performances with more variable than the leadership.

\section{RESULTS}

Table 2: Statistics and Single Sample Leadership Test

\begin{tabular}{|c|c|c|c|c|c|}
\hline \multirow{3}{*}{ Single Sample Statistics } & & \multicolumn{4}{|c|}{ Single sample test } \\
\hline & & & & Test & \\
\hline & $\mathrm{M}$ & SD & $\mathrm{t}$ & ddl & Sig. (bilateral) \\
\hline idealized Influence & 2.82 & .574 & 10.239 & 344 & .000 \\
\hline inspiring motivation & 1.33 & .302 & 72.329 & 344 & .000 \\
\hline intellectual stimulation & 2.7 & .674 & 5.567 & 344 & .000 \\
\hline individual consideration & 2.55 & .654 & 1.467 & 344 & 0.143 \\
\hline Transformational leadership & 2.35 & .477 & -5.884 & 344 & .000 \\
\hline $\begin{array}{l}\text { dependence of head of establishment } \\
\text { on unconditional rewards }\end{array}$ & 2.6 & .596 & 3.188 & 344 & 0.002 \\
\hline management per active exception & 2.78 & .624 & 8.239 & 344 & .000 \\
\hline Management per passive exception & 2.3 & .588 & -6.201 & 344 & .000 \\
\hline Transactionnel leadership & 2.56 & .406 & 2.786 & 344 & 0.006 \\
\hline
\end{tabular}

The hypothetical average used for the single sample test is 2.5 , the median of the items scale measuring leadership. Regarding transformational leadership, the modalities of idealized influence, intellectual stimulation and individual consideration refer to scores significantly higher than the value of the test. The 
Silamine,M.T.H. \& Rodrigue,N.N.H.(2021).Leadership styles and organizational performance of employees: The case of some primary and secondary schools in Cameroon. International Journal of Educational Research Review,6(1),30-45.

individual consideration is equal to the value of the test while the inspiring motivation is much lower, if not low. Transactional leadership is still effective, but not particularly high.

For transactional leadership, the average sample score is significantly higher than 2.5. It is just above the hypothetical average without being, as before, high. The Head's Dependence on Unconditional Rewards and Active Exception Management are also greater than 2.5 while Passive Exception Management is not.

Table 3. Statistics and Single Sample Test for Organizational Performance Single Sample

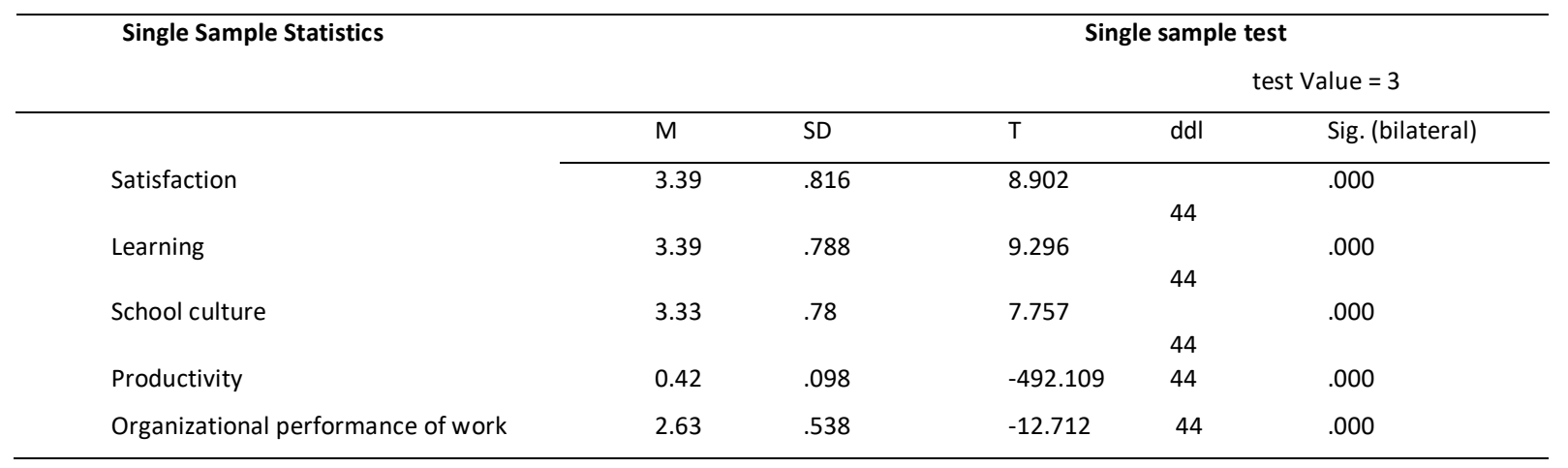

Sampling average of the organizational performance of the work is lower than the test value, 3 this time. Yet three out of the four dimensions that make up it refer to averages that are significantly higher than the hypothetical average. It turns out that the productivity scores are low, especially since the dimension in question reduces the overall score of the organizational performance of work. 


\section{E RE International Journal of Educational Research Review}

Table 4. Correlation matrix

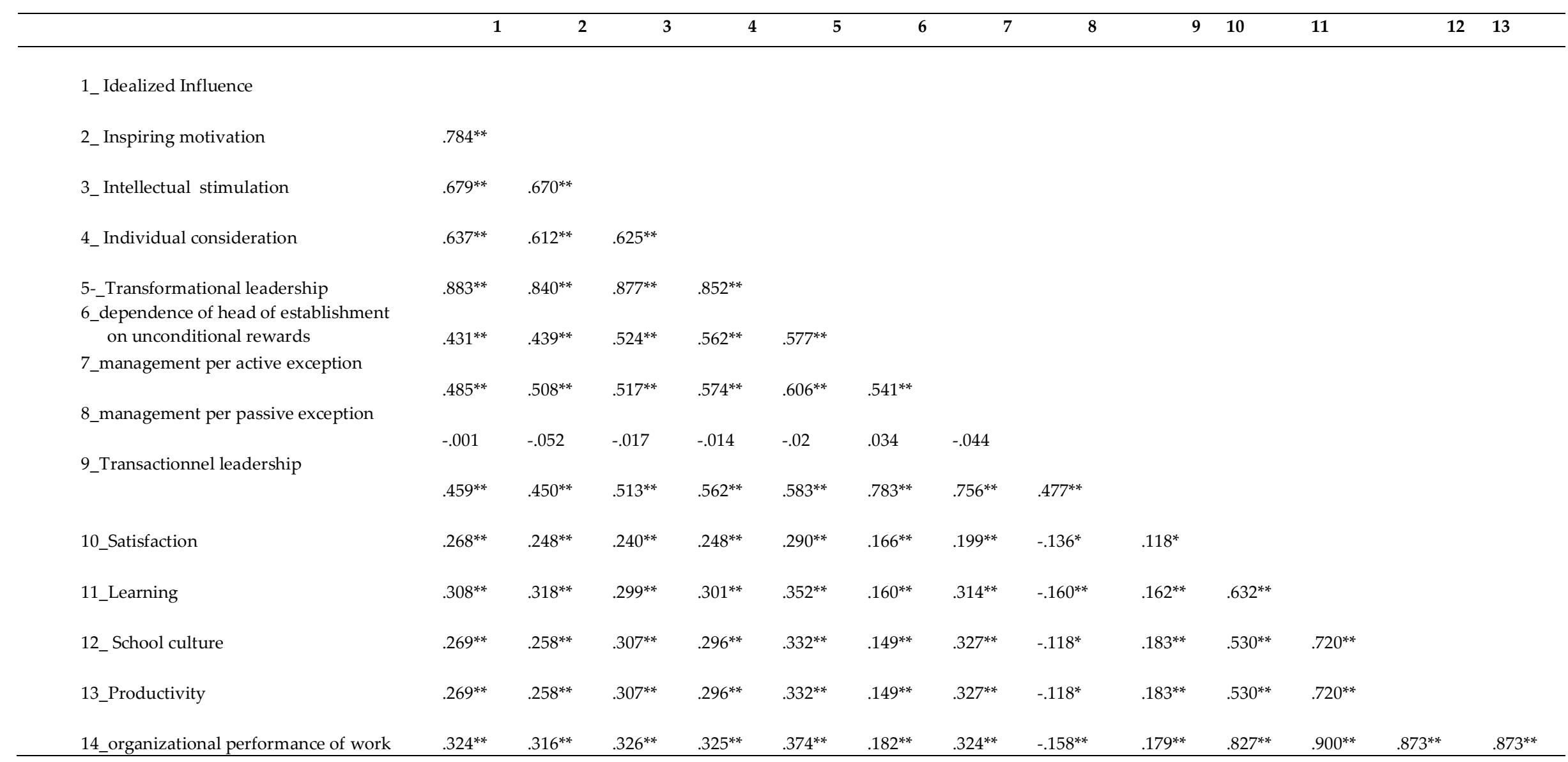




\section{International Journal of Educational Research Review}

The correlation matrix indicates that there is a strong correlation between the transformational leadership style and its modalities that are: idealized influence, inspiring motivation, intellectual stimulation and individual consideration. Transactional leadership style also indicates that there is a strongly correlation between the transactional leadership style and its modalities that are: The Head's Dependence on Unconditional Rewards active Exception management and passive exception management. Organizational performance of work indicates that only three modalities are correlated with it. The productivity is not correlated.

\section{Demographic variables}

The type of institution is closely related to transformational leadership $\left(\mathrm{F}_{(2 ; 313)}=5.17 ; \mathrm{p}=.006\right)$ and transactional $\left(\mathrm{F}_{(2 ; 313)}=4.18 ; \mathrm{p}=.016\right)$ and the organizational performance of employees' work $\left(\mathrm{F}_{(2 ; 313)} 5.32 ; \mathrm{p}=\right.$ .005 ). The Bonferroni comparison tests indicate that Catholic denominational private institutions have higher scores in transformational leadership than those in the public sector ( $\mathrm{MD}=.273 ; \mathrm{p}=.005)$ and those in the secular private sector. $(\mathrm{MD}=.247 ; \mathrm{p}=.019)$. In terms of transformational leadership, Catholics once again score better than the public $(\mathrm{MD}=.2 ; \mathrm{p}=.022)$ and the secular private sector $(\mathrm{MD}=.214 ; \mathrm{p}=.019)$. Regarding the organizational performance of the employees' work, only the average difference between Catholics and the public sector is significant, the scores being better among the former than the latter (MD =.269; $\mathrm{p}=.04$ ).

Regarding the type of institution, only transformational leadership is found to be significantly different depending on whether we are in Primary, General Secondary and Technical Secondary $\left(\mathrm{F}_{(2 ; 313)}=5.84 ; \mathrm{p}=\right.$ $.003)$; which is not the case for transactional leadership $\left(\mathrm{F}_{(2 ; 313)}=.2 ; \mathrm{p}=.816\right)$ and the organizational performance of employees' work $\left(\mathrm{F}_{(2 ; 313)}=.84 ; \mathrm{p}=.432\right)$. Bonferroni comparison tests indicate that transformational leadership scores are better in Elementary than General Secondary $(\mathrm{DM}=.201 ; \mathrm{p}=.004)$.

According to whether the education system is Francophone, Anglophone or bilingual, no significant difference is recorded in terms of transformational leaderships $\left(\mathrm{F}_{(2 ; 313)}=.053 ; \mathrm{p}=.948\right)$ and transactional ( $\left.\mathrm{F}_{(2 ; 313)}=.812 ; \mathrm{p}=.445\right)$ and organisational performance of employees' work $\left(\mathrm{F}_{(2 ; 313)} .68 ; \mathrm{p}=.508\right)$.

Gender is only significantly linked to transformational leadership $(\mathrm{t}=-2.342 ; \mathrm{ddl}=343 ; \mathrm{p}=.02)$, with women $(\mathrm{M}=2.40 ; \mathrm{S}-\mathrm{D}=.49)$ scoring better than men $(\mathrm{M}=2.27 ; \mathrm{S}-\mathrm{D}=.447)$. These scores do not distinguish between female teachers and male teachers in terms of transactional leadership $(t=.124 ; \mathrm{ddl}=343 ; \mathrm{p}=.902)$, and work organizational performance $(t=-.735 ; \mathrm{ddl}=343 ; \mathrm{p}=.463)$. The region of origin of the respondents, knowing that Cameroon has ten, does not explain at all the variation in transformational $\left(\mathrm{F}_{(9 ; 306)}\right)=1.13 ; \mathrm{p}=$ $.341)$ and transactional $(\mathrm{F}(9 ; 306))=1.227 ; \mathrm{p}=.277)$ and the organisational performance of employees' work $(\mathrm{F}(9 ; 306)=.535 ; \mathrm{p}=.848)$.

Marital status, depending on whether teachers are married, single or divorced, also does not explain the variation in transformational $\left(\mathrm{F}_{(3 ; 312)}=1.736 ; \mathrm{p}=.159\right)$ and transactional $\left.\left(\mathrm{F}_{(3 ; 312)}\right)=2.062 ; \mathrm{p}=.105\right)$ and the organisational performance of employees' work $(\mathrm{F}(3 ; 312)=.329 ; \mathrm{p}=.804)$. 
Silamine,M.T.H. \& Rodrigue,N.N.H.(2021).Leadership styles and organizational performance of employees: The case of some primary and secondary schools in Cameroon. International Journal of Educational Research Review,6(1),30-45.

For the highest degree, only transformational leadership is significantly different depending on the parchment $\left(\mathrm{F}_{(4 ; 339)}=5.834 ; \mathrm{p}<.001\right)$; this is not the case for transactional leadership $\left(\mathrm{F}_{(4 ; 339)}=.276 ; \mathrm{p}=.893\right)$ and performance organisation of employees' work $\left(\mathrm{F}_{(4 ; 339)}=1.332 ; \mathrm{p}=.258\right)$. Bonferroni comparison tests indicate that transformational leadership scores are lower among Master's holders than among those with Probationary $(\mathrm{DM}=-.35 ; \mathrm{p}<.001)$, Baccalaureate $(\mathrm{DM}=-.216 ; \mathrm{p}=.042)$ and Bachelor $(\mathrm{DM}=-.229 ; \mathrm{p}=.012)$.

The position occupied by the respondent is only significantly related to organizational performance at work $(\mathrm{F}(6 ; 338)=3.02 ; \mathrm{p}=.007)$. This is not the case with transformational leaderships $(\mathrm{F}(6 ; 338)=1.072 ; \mathrm{p}=.379)$ and transactional $(\mathrm{F}(6 ; 338)=5.834 ; \mathrm{p}=.007)$. In terms of performance, the Bonferroni tests are silent as to significant average differences.

Seniority at the post is significantly correlated with transformational $(\mathrm{r}=.162 ; \mathrm{p}=.003)$ and transactional $(\mathrm{r}=.109 ; \mathrm{p}=.043)$ leaderships and not with organizational performance at work $(\mathrm{r}=.085 ; \mathrm{p}=$ $.116)$.

The number of years of service under the current Head of School is negatively and significantly correlated with organizational performance at work $(\mathrm{r}=-.17$; $\mathrm{p}=.002)$ and not at all with transformational leaderships $(\mathrm{r}=-.019 ; \mathrm{p}=.727)$ and transactional $(\mathrm{r}=-.055 ; \mathrm{p}=.311)$.

The number of teaching hours per week is in no way correlated with transformational $(\mathrm{r}=.54 ; \mathrm{p}=.315)$ and transactional $(\mathrm{r}=-.1 ; \mathrm{p}=.064)$ leaderships and organizational performance at work $(\mathrm{r}=.04 ; \mathrm{p}=.459)$. Religious engagement has nothing to do with transformational $(\mathrm{F}(4 ; 311)=2.029 ; \mathrm{p}=.09)$ and transactional $(\mathrm{F}(4 ;$ $311)=.88 ; \mathrm{p}=)$. Organizational performance at work $(\mathrm{F}(4 ; 311)=2.151 ; \mathrm{p}=.075)$.

The gender of the school head only explains the transformational leadership scores $(t=-2.27 ; \mathrm{ddl}=314$; $\mathrm{p}=.024)$, knowing that the scores are better in the institutions headed by women $(\mathrm{M}=2.39$; $\mathrm{S}-\mathrm{D}=.462)$ than those in male-run institutions ( $\mathrm{M}=2.27$; S.-D. = .494). On the other hand, the gender of the school head does not explain the variation in the scores in terms of transactional leadership $(\mathrm{t}=-1.776$; $\mathrm{ddl}=314 ; \mathrm{p}=.077)$ and organizational performance of work $(t=.043 ; \mathrm{ddl}=314 ; \mathrm{p}=.996)$.

Regression of organizational performance on leadership and significant socio-demographic variables.

Table 5. Summary of template

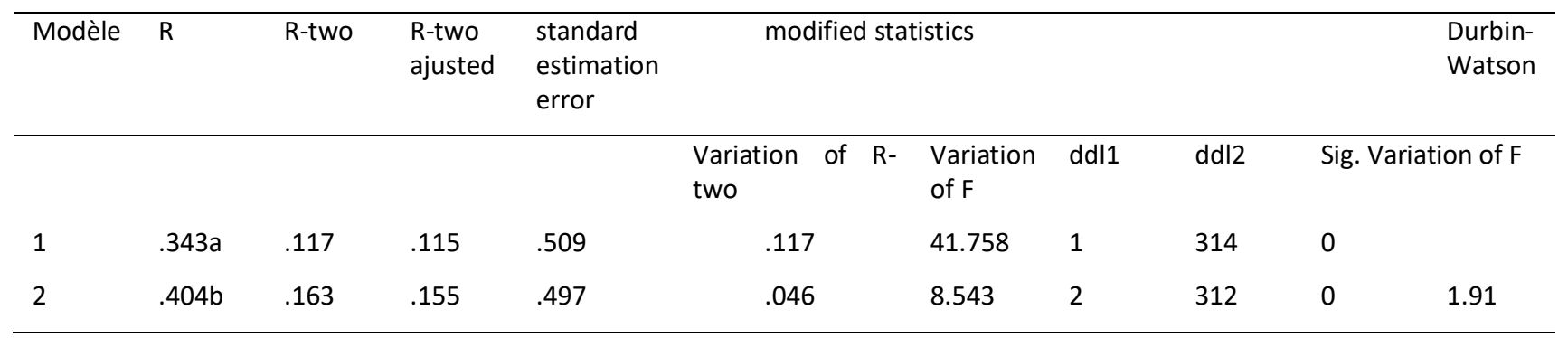

a Predictors: (Constant), Transformational Leadership 
Silamine,M.T.H. \& Rodrigue,N.N.H.(2021).Leadership styles and organizational performance of employees: The case of some primary and secondary schools in Cameroon. International Journal of Educational Research Review,6(1),30-45.

b Predictors: (Constant), Transformational Leadership, Years of Service Under Current School Head, School Categories

c Dependent Variable: Organizational Performance of Work

Table 6. Template Parameter

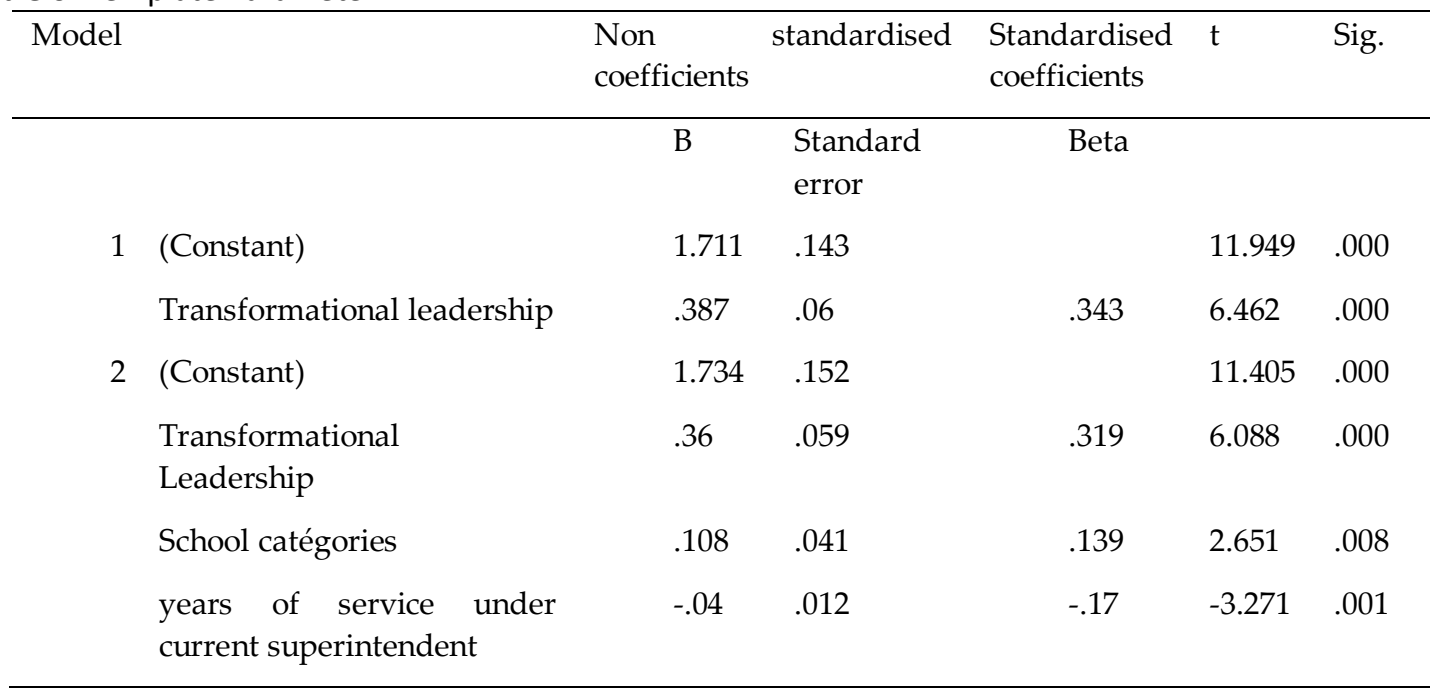

The data analysis continues with a hierarchical regression model consisting of two blocks of variables, with the method entered for the first step, namely Block 1 (transformational leadership and transactional leadership). The second stage introduces Block 2, the socio-demographic variables selected (type of institution, highest degree, number of years of service under the current head of institution). Following the analysis, the transaction leadership variables in Block 1 and the highest degree in Block 2 were eliminated from the analysis because of their insignificant contribution.

The resumption of the analysis presents correlations between the independent variables showing that there is no significant risk of multi-linearity, no correlation between two of these variables being at .9 or -.9 . The values of multiple correlation (R), which are .343 for the first model and .404 for the second, provide information on the strength of the relationship between the organizational performance of the work and the combination of the independent variables of each model. They further suggest that the data are satisfactorily adjusted to the model. Then, the meaning of the R2 is evaluated according to the contribution of each step. The $\mathrm{F}$ variation associated with the first model is significant $(\mathrm{p}<-.001)$. The first model, consisting of the independent variable transformational leadership, explains a significant proportion of the variance in work organization performance $(\mathrm{R} 2=.117 ; \mathrm{F}<.001)$. The second model, which also covers the type of establishment and the number of years of service under the current head of school, increases the R2 from .117 to 0 , and 163 . This change of .046 appears to be significant $(\mathrm{F}=.001)$. The second stage thus contributes significantly to the improvement of the explanation of the organizational performance of work in the establishments. 
Silamine,M.T.H. \& Rodrigue,N.N.H.(2021).Leadership styles and organizational performance of employees: The case of some primary and secondary schools in Cameroon. International Journal of Educational Research Review,6(1),30-45.

The Durbin-Watson test indicates a statistic with a value of 1.91 that is acceptable and allows us to respect the premise of independence of error. Thus, $11.70 \%$ of the variability in organizational performance at work in institutions is explained by transformational leadership. Added to the latter, the type of establishment/school and the number of years of service under the current head of school explain $16.30 \%$ of the said variability.

It is possible to construct the regression equation to predict a value of organizational performance at work. It expresses itself in this way: Credit $=(1.734+0.36$ transformational leadership +.108 type of institution - .04 years of service under current head of institution). Organizational performance at work in institutions increases with transformational leadership and type of institution and decreases as the number of years of service under the current head of school increases.

\section{Result, Discussion and Conclusion}

The purpose of this research is to predict the organizational performance of employees' work according to the leadership style of primary, general secondary and technical schools head teachers in Cameroon. In this research, we found the following result that the existence of a significantly positive relationship between transformational leadership, and its different modalities. These findings are confirmed by Bass and Riggio (2006). For them, transformational leadership is about inspiring followers to engage, share a vision and goals for an organization or unit, challenge them to solve problems in innovative ways and develop the leadership capacity of practitioners through coaching, mentoring, challenge and support delivery. The result also indicate the existence of a positive relationship between transactional leadership and its different modalities. These results confirms what Bradley and Charbonneau in 2004. For them, transactional leadership is characterized by exchanges in which leaders motivate subordinates by rewarding them for their efforts or punishing them for their lack of effort. Finally, the results indicate the existence of a weak link between organizational performance and its different modalities. This is due to the fact that the organizational performance" is far from being as simple as one might think because even if the literature abounds on this subject there is no consensus on the definition of the subject or on how to measure it (Morin and al 1999; Boujlida 2002).

With regard to demographic variables, the results of this study show that the type of institution, the highest degree, the number of years of service under the current superintendent are the three variables that were selected from the thirteen demographic variable, we tested that are related to transformational leadership, transactional and organizational performance of employees' work.

For the development of a hierarchical equation predicting organizational performance using significant independent variables, the results of this study show that it is possible to construct the regression equation to predict a value of organizational performance at work because the first model, consisting of the independent variable that is transformational leadership, explains a significant proportion of the variance in 
Silamine,M.T.H. \& Rodrigue,N.N.H.(2021).Leadership styles and organizational performance of employees: The case of some primary and secondary schools in Cameroon. International Journal of Educational Research Review,6(1),30-45.

work organization performance as well as the second model that in addition to transformational leadership includes the type of institution and the number of years of service under the current school head.

In short, the results obtained from this research allow us to affirm that there is a link between the modalities of transformational leadership, and the organizational performance of work in schools in the city of Yaoundé. Some reaches support this finding. Thus, Rejas, Ponce and Almonte (2006) found that transformational leadership has a positive impact on performance, whereas transactional leadership and laissez faire style had a negative impact. Similarly, Muterera (2012), in his studies found that transformational leadership behaviors have a significant impact on organizational performance. He said in addition that leaders who use transformational leadership as their primary or dominant leadership style have an impact on organizational performance over and beyond the impact of those leaders who mostly use transactional style. Whereas results contradict with some others studies mentioned by: Obiwuru, Okwu,Akpa and Nwankere (2011). In their study, they conclude that transactional leadership style is more appropriate in inducing performance in small scale enterprises than transformational leadership style. A possible reason for this is that the employee of small scale enterprises are usually not skilled and experienced professionals. Therefore, contingent recognition/reward and management by exception rather than charisma, inspirational motivation and intellectual stimulation. The same, Paracha and al (2012) in their researches found that transactional and transformational both are significantly positive associated with employee performance, however transactional leadership was more significant than transformational. The results of Paracha and al (2012) also informed that employee performance is heavily relying on leadership and it can play a vital role in determining the performance of employees, so organization must carefully analyze, what kind of leadership they should adopt if they want to increase employee performance and the result suggests us organization must opt transactional leadership style so that employee performance can be increased.

Like any other research, this research has its own limits and perspectives. Thus, the limitation of this study is related to the nature of the sample, as our sample $(n=345)$ is only for schools in the city of Yaoundé. Therefore, for future research, we recommend that the results be replicated on a larger sample. For example, they will be able to extend this study to several institutions from all regions of Cameroon.

To conclude, our research is distinguished from other research by the following points. First of all, it is not done in the same context as other research. It is made in Cameroon and in addition it uses a large sample from schools of public primary, private primary and bilingual schools, school of public general secondary education, private education, bilingual and technical secondary education. Secondly, the respondents are the employees who occupy various positions within the educational establishment, namely: vice principals, general supervisors, guidance and counsellors, post managers, bursars, sector supervisors, permanent and temporary teachers. The study concludes that transformational leadership style is more appropriate to increase the organizational performance of employee in all the schools work that we use in our study. 
Silamine,M.T.H. \& Rodrigue,N.N.H.(2021).Leadership styles and organizational performance of employees: The case of some primary and secondary schools in Cameroon. International Journal of Educational Research Review,6(1),30-45.

Consequently, leaders should use the different factors of transformational leadership to stimulate their staff to become more involved in school work to deliver results beyond their own expectations.

\section{References}

Abasilim, U.D. (2014). Transformational leadership style and its relationship with organizational performance in Nigeria work context: A review. IOSR Journal of Business and Management (IOSR.JBM) E-ISSN : 2278-487X,p-ISSN :2319-7668.volume16.issue 9.ver.pp 01-05 retrieved from www.iosrjournals.org

Akanni, A. (1997).Culture d'entreprise et performance au Sénégal. Caen: Université de caen, 363p.mltigr.Th.:Gest.,Caen.1997/10/25. Tiré du site http:/horizon.documentation.ird.fr/exldoc/pleins_testes/divers17-08/010011698

Bass, B.M. (1985). Leadership and performance beyond expectations. New-York: Free Press

Bass, B.M. (1997). Does the transformational-transactional leadership paradigm transcend organization and national boundaries? American Psychologist Association, 52(2):130-139

Bass, B.M. \& Riggio.R.E. (2006). Transformational leadership. Second Edition. London: Lawrence Erlbaum. Associates. Publishers.

Benlalam, L. (2015). La gestion des connaissances, un outil de performance organisationnelle (Mémoire présenté dans le cadre du programme de maîtrise en gestion de projet en vue de l'obtention du grade de maître en sciences. Université du Québec à Rimouski). Répéré à semaphore.uqar.ca> eprint PDF

Boujlida,A. (2002). La performance financière des PME Manufacturières : Conceptualisation et mesure. Memoire. Université du Quebec à Trois Rivières retrieved from https://oraprdnt.uqtr.uquebec.ca> PDF

Da Silvan,L. et Santugini. M. (2009). Qu'est-ce que la productivité? Centre sur la productivité et la prospérité. HEC Montréal

Doody, O. E.\& Doody, C.M (2014). Transformational leadership in nursing practice. Br J Nurs, 20(11):661-4

Ganos,J.\& Gallo.P(2013). Model for leadership style evaluation- EFST. Management, Vol, 18,2013,2, pp. 157-168. retrieved from https://moj.efst.hr>10-gonos consulté le 22 mars 2020.

Jamaludin, Z. (2011). Do transactional, transformational and spiritual leadership styles distinct? A conceptual insight. Journal of global business and economics, 2(1), 73-85.

François, C. (2003). La Formation Professionnelle Continue. L'activité des dispensateurs de formation continue en région Centre de 1990 à 2000. ALFA CENTRE. Retrieved from www.alfacentre.org> bpt1203.

Kagher, Z. (2009). La formation continue et son impact dans l'entreprise (Mémoire online. Université Abderrahmane Mira de Béjaia Algérie) retrieved from https://www.memoireonline.com>

Khoza, N.S. (2015). The impact of transformational and transactional leadership styles on selected job attitudes in a steel manufacturing organization.Mini dissertation submitted in partial fulfilment of the requirements for the degree master of Business Administration and the Potchefstroom Campus of the North-West University. Retrieved from https://www.semanticscholar.org

Lamothe, R. (2017). Leadership de la direction d'école dans la mise en place et la progression des communautés d'apprentissage professionnelle dans quatre écoles francophones de l'Ontario : étude multicas. retrieved from: http://dx.doi.org/10.20381/ruor-20504 
Silamine,M.T.H. \& Rodrigue,N.N.H.(2021).Leadership styles and organizational performance of employees: The case of some primary and secondary schools in Cameroon. International Journal of Educational Research Review,6(1),30-45.

Lievens, F; Geit, P. et Coestsier, P. (1997). Identification of transformational leadership qualities: An examination of potential biases. European Journal of Work and Organizational Psychology, 6(4), 415430.

Muterera, J. (2012). Leadership behaviors and their impact organizational performance in Governmental entities. International Journal of Sustanaible Development,pp.19-24. Retrieved from retrieved from https://papers.ssrn.com

Morin,R. et Dussault,M. (1999). Leadership de la direction et sentiment d'autoefficacité des enseignants. Cahiers de la recherche en éducation,6(3),373-392. Retrieved from https://doi.org/10.7202/1016976ar

Paracha, M.M; Qamar, A; Mirza, A et Waqas, I. (2012). Impact of leadership style (transformational and transactional leadership) on employee performance and mediating role of job satisfaction. Study of private school (Educator) in Pakistan. Global Journal of Management and Business Research, 12(4):54-64.

Pradeep,D.D. \& Prabhu,N.R.V.(2011). The relation between effective leadership and employee performance.International conference on advancements in information technology with workshop of ICBMG2011. IPCSIT vol, 20(2011). (2011) IACSIT press, Singapore

Rejas,L.P ; Ponce,E.R ; Almonte, M.D \& Ponce, J.R. (2006). Transformational and transactional leadership: A study of their influence in small companies. Ingeniare-Revista Chilena de Ingenieria, vol.14 $N^{\circ}$, 2006, pp.159-166. Retrieved from https://scielo.conicyt.cl

UNESCO (2006).Les nouveaux rôles des chefs d'établissement dans l'enseignement secondaire. France. (ED2006/WS/66) - CLD 30403)

Zineb, I. (2017). La performance de l'entreprise : un concept complexe aux multiples dimensions. retrieved from https://www. Cain. Info>revue projectique 2017/2 (n 17), Pages 93 à 103 